Revista de Comunicación y Salud, 2021, Vol. 11, 29-53

Editado por Cátedra de Comunicación y Salud

ISSN: 2173-1675

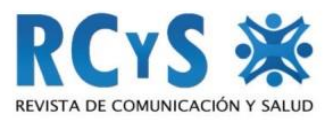

Enviado 16/11/2020

Aprobado 16/02/2021

Publicado 19/04/2021

\title{
EL IMPACTO DE LA PUBLICIDAD EN LOS HÁBITOS ALIMENTICIOS DE LOS ESPAÑOLES: UNA CUESTIÓN DE EDUCACIÓN ALIMENTARIA
}

\section{Impact Of Advertising On Spanish People's Eating Habits: A Question Of Food Education}

\author{
Manuel Carmona Rodríguez \\ Universidad Rey Juan Carlos. España. \\ Juana Ma Anguita Acero \\ Universidad Rey Juan Carlos. España.
}

\section{Cómo citar el artículo}

Carmona Rodríguez, M. y Anguita Acero, J. Ma․ (2021). El impacto de la publicidad en los hábitos alimenticios de los españoles: una cuestión de educación alimentaria. Revista de Comunicación y Salud, 11, 29-53. https://doi.org/10.35669/rcys.2021.11.e267

\section{Resumen}

El mundo actual vive preocupado por su imagen y su salud. Si bien lo físico ha prevalecido sobre lo saludable durante años, hoy los hábitos alimenticios saludables se imponen. En este sentido, el usuario demanda más información y más precisa. Por ello, el sector alimentario está obligado a dotar a sus productos de un etiquetado detallado que, en ocasiones, puede tornarse engañoso. El objetivo de este trabajo consiste en determinar qué buscan los consumidores, por qué y si son conscientes de lo que compran. Para ello, se ha utilizado una metodología tanto cualitativa como cuantitativa a través de la entrevista dirigida en profundidad, la cual ha sido realizada tanto a usuarios de a pie como a un especialista de reconocido prestigio en el sector, el Dr. Tinahones. Se trata, por tanto, de un primer acercamiento al estado de la cuestión en el contexto de 2019 cuyos resultados muestran que, en general, el etiquetado y la publicidad juegan un papel determinante en la elección de los productos que se consumen y que, en muchos casos, hay una gran desinformación, e incluso información tergiversada, de lo que implica una dieta saludable. En términos generales, es necesaria una formación en alimentación 
El impacto de la publicidad en los hábitos alimenticios de los españoles: una cuestión de educación alimentaria

desde edades tempranas e información más clara en el etiquetado de los productos de consumo.

Palabras clave: Salud; Consumidores; Publicidad; Sector Alimenticio; Entrevista; Etiquetado; Dieta equilibrada.

\begin{abstract}
Today's world is concerned about its body image and health. Thus, food sector has been obliged to provide its products with a detailed labelling that, sometimes, could be misleading. This work is aimed at determining what consumers look for, why and if they are really conscious of what they buy. To do so, both a qualitative and a quantitative methodology have been used through an in-depth guided interview. The results show that, in general, labelling and publicity play an important role when choosing the products that are consumed in the context of 2019.
\end{abstract}

Keywords: Health; Consumers; Publicity; Food Sector; Interview; Labelling; Balance diet.

\title{
1. INTRODUCCIÓN
}

El fenómeno de la globalización viene caracterizado por el hecho de que un importante y creciente número de países de todo el mundo comparten aspectos de orden político (Baylis, Smith y Owens, 2017; Ball, 2014), económico (Rodrik, 2011), social (Samour, 2013), cultural (Pineda, 2002; Pieterse, 2019) e incluso lingüístico (Higgins, 2011), entre otros. Dentro de dicho fenómeno la publicidad ocupa un lugar destacado y se ha convertido en el baluarte necesario para difundir y promocionar ciertos hábitos, tales como los relacionados con la dieta y los estilos de vida saludables. La industria alimentaria y su vinculación al consumo de determinados productos, ante el potencial peligro de desarrollar ciertas afecciones o enfermedades, y su incidencia en la expectativa de vida acaparan buena parte de los mensajes publicitarios que nos rodean (Chan, Prendergast, Grønhøj y Bech-Larsenc, 2010).

La salud se ha convertido en un tema cuyo interés crece exponencialmente día a día, potenciado por los medios de comunicación y las redes sociales (Schoenebeck, 2014). De ahí que sea posible afirmar que la publicidad es, sin lugar a dudas, el gran aliado de lo que ingerimos (Menéndez y Franco, 2009). Sin embargo, la publicidad y su contenido deben regularse tanto a nivel nacional como supranacional (Boddewyn, 1988) a fin de evitar transmitir ideas erróneas, con o sin intención (Wansink, 2006), cuyas consecuencias, dada la inmediatez de las noticias, pueden ser devastadoras (Martín y Hernández, 2014). El incumplimiento de la normativa regulatoria nacional y europea en materia de publicidad comercial alimentaria, a lo que se suman las lagunas aún existentes en ciertos aspectos (González, 2015), sobre todo los derivados del uso de las redes sociales, dificultan el control de lo que se debe transmitir y cómo (Hernández, 2013a; Martín y Hernández, 2014). 
El impacto de la publicidad en los hábitos alimenticios de los españoles: una cuestión de educación alimentaria

La seguridad en cuanto a saber lo que se come y se bebe se ha convertido en un reto y un motivo de preocupación para la sociedad actual (Hernández, 2013b). Así, González, Meléndez y Álvarez-Dardet (2012) consideran que a la sociedad del siglo XXI le inquieta mucho todo lo relacionado con la salud, circunstancia que ha desencadenado la emergencia de "alimentos funcionales". Es decir, aquellos que, por su composición, son recomendables para la salubridad del ser humano.

La demanda y el interés generado por dichos alimentos desde finales del siglo pasado han propiciado la aparición de comestibles y bebibles bajos en grasas, calorías y azúcares, y ricos en ciertas sustancias que pronto desembocaron en todo tipo de "[...] productos probióticos, prebióticos, fitoesteroles y fibras" (González, Meléndez y ÁlvarezDardet, 2012).

La irrupción de esta nueva forma de alimentación lleva parejo un creciente interés por un etiquetado claro y detallado, y por dotar de una mayor visibilidad a los beneficios de ciertos productos (Thorndike, Riis, Sonnenberg y Levy, 2014). La demanda social por conocer mejor para elegir de forma acertada fue lo que llevó a Thaler y Sunstein (2009) a acuñar el término choice architecture, conocido en español como arquitectura de la elección. De esta arquitectura se desprende que, a partir de una buena presentación de opciones posibles, la elección de los consumidores estará mejor fundamentada.

El etiquetado cobra un papel esencial en la presentación de los productos que se consumen (Dani, 2019; Lobstein y Davies, 2009), su presencia es obligatoria y su función es doble: por una parte, la meramente promocional y, por otra, la informativa (Reglamento UE 1169/2011; Sarkodie y Boakye-Kessie, 2017). Atendiendo no sólo al Reglamento UE 1169/2011 sino también a la normativa española, Real Decreto 1334/1999, ha habido comunidades autónomas (como la Comunidad de Madrid) que han elaborado guías para informar a los ciudadanos. En lo relativo a la información obligatoria que debe aparecer visible y utilizando como base la Guía sobre el etiquetado nutricional de los alimentos de la Comunidad de Madrid (2017), los usuarios deberían poder ver: valor energético, cantidad de grasas, cantidad de grasas saturadas, hidratos de carbono, azúcares, proteínas y sal. En lo que respecta a información voluntaria, pueden aparecer grasas monoinsaturadas, poliinsaturadas, polialcoholes, fibra alimentaria, vitaminas y minerales.

La guía es clara a ese respecto y añade que no debe aparecer nada más, con la salvedad de los productos enriquecidos, los cuales deberán contar no sólo con la información obligatoria sino con aquella adicional propia de la aportación extra. También se pueden añadir las propiedades saludables de ciertos componentes y sus proporciones (por ejemplo, el ácido oleico). Con independencia del producto del que estemos hablando, el tamaño de la letra de dicha información (mínimo 1,2 milímetros o, en el caso de envases más pequeños, 0,9) también cobra especial relevancia de cara a las decisiones de compra que adopten los consumidores potenciales (Mulders, 2019; Hansson, 2019).

Si bien lo que se persigue es mejorar los hábitos nutricionales de todos los individuos que conforman la sociedad avanzada del siglo XXI (Teixeira, Patrick y Mata, 2011; Pelletier et al, 2004), el presente muestra una realidad paradójica y desconcertante

Revista de Comunicación y Salud, 2021, Vol. 11, 29-53 
debido a que cada vez son más los problemas relacionados con el sobrepeso o la ingesta de productos altamente perjudiciales para la salud (Aranceta et al, 2007). A estos problemas se suman, además, los de orden cardiovascular, estomacal o dermatológico, entre muchos otros (Newell, 2010). En la búsqueda de una respuesta a estas circunstancias se evidencia la existencia de desinformación, la publicidad engañosa y/o la falta de formación en materia alimentaria (Wansink, 2006).

Cabe destacar cuáles son los grupos sociales más vulnerables a la hora de dejarse llevar por la desinformación y la publicidad engañosa: los niños, adolescentes y jóvenes, en general (Hayes y Ross, 1987; Martínez, Fernández del Olmo y Anuncibay, 2007), los cuales desconocen las consecuencias de una mala alimentación y no se cuestionan por qué sus hábitos deben cambiar. A esto se suma un doble problema generalizado hoy en día. El primero, a los menores sus mayores han de educarlos en la práctica de buenos alimentos alimenticios y saludables. Eso implica tener que decirles "no" en determinados momentos a requerimientos que hacen los descendientes sobre determinadas prácticas alimenticias poco saludables o en el peor de los casos nocivas. Ese "no" ha de ser asumido como un límite positivo, puesto que toda medida que suponga una mejora en las condiciones y circunstancias de vida de cualquier persona, lleva implícita la asunción de unos usos y costumbres inteligentes, que yendo a la raíz semántica latina del término supone elegir bien. Ser inteligente no es otra cosa, como mostró Ortega siguiendo la raíz latina original de las palabras elegans e intellegans, que elegir la mejor opción (Ortega, 1952).

El segundo, ser un buen padre o una buena madre, siguiendo con el análisis anterior, implica educar a los descendientes en una filosofía y cultura de alcanzar el equilibrio en la vida cotidiana, y ello afecta a los hábitos alimenticios. La ponderación entre derechos y responsabilidades es crucial para vivir con inteligencia. Siguiendo a Ortega (1986) y aplicando su definición de persona noble a los usos alimentarios y nutricionales, aquélla lo será cuando aprenda en su día a día a asumir las obligaciones que conlleva tener una dieta sana. Las consecuencias de no cumplir con ese menú rico y variado, propio de la dieta mediterránea, es convertirse en un ser humano con problemas nutricionales y de mala alimentación que por norma general provocan sobrepeso, obesidad, enfermedades cardiovasculares, patologías psicomotrices, etc.

\subsection{Finalidad y objetivos}

La finalidad última de este trabajo consiste en mostrar que a mayor información nutricional no necesariamente hay siempre unos hábitos alimentarios más saludables. Para ello, es necesario dar cabida a los siguientes objetivos específicos: conocer si la población de a pie considera que tiene unos hábitos alimentarios saludables, determinar si la publicidad influye en la dieta de los ciudadanos y, por último, determinar qué importancia tiene el etiquetado para los consumidores. 
El impacto de la publicidad en los hábitos alimenticios de los españoles: una cuestión de educación alimentaria

\section{MATERIAL Y MÉTODO}

El presente artículo ofrece un estudio de carácter etnográfico (Cerri, 2010) cuyo eje vertebrador gira en torno a la importancia que tienen los testimonios y opiniones personales de los consumidores y de un especialista en lo que a dieta saludable se refiere.

Para ello, se han elaborado y llevado a cabo dos entrevistas dirigidas no estructuradas o abiertas y, dentro de ese modelo, se ha optado por la entrevista en profundidad (Robles, 2011). La entrevista dirigida no estructurada o abierta permite obtener datos de todo tipo puesto que el entrevistado tiene la libertad de responder lo que desee y como desee. Si bien el entrevistador sabe el por qué de las preguntas que formula y lo que desea conseguir a través de ellas, está abierto a cualquier información que pueda ser de utilidad.

Es por ello que la flexibilidad es fundamental en este tipo de método. Atendiendo a Taylor y Bogdan (1984), la entrevista en profundidad es compleja porque de una conversación abierta y natural donde el entrevistador puede recibir información sesgada o no totalmente cierta, éste tendrá que dilucidar de forma crítica qué datos son veraces. En este trabajo, los datos que se obtengan a través de las entrevistas realizadas serán analizados tanto cuantitativa como cualitativamente. Si bien, lo habitual es que a través de la entrevista en profundidad el análisis sea cualitativo.

\subsection{Participantes}

Se han entrevistado en 2019 en España a un total de 15 personas con edades comprendidas entre los 31 y los 66 años con estilos de vida muy diversos que pueden corresponder con cualquier ciudadano de a pie. Además, se ha entrevistado al Dr. Francisco Tinahones, Jefe de Endocrinología y Nutrición del Hospital Carlos Haya de Málaga, Presidente de la Sociedad Española para el Estudio de la Obesidad y el Sobrepeso, y Ponente de España en la Comisión de Dietética y Nutrición de la Unión Europea.

De esta manera, se pretende visualizar, por un lado, el grado de conocimiento y concienciación de los ciudadanos sobre los hábitos alimenticios cotidianos, junto con otros hábitos de vida que indicen directamente en la salud; $y$, por otro, permite profundizar desde un punto de vista científico sobre la realidad estudiada.

Las 15 personas entrevistadas pertenecen a tres generaciones claramente diferenciadas (Ortega y Gasset, 1947 y Marías, 1961):

a) Generación de 1960. Se trata de un profesor y una ama de casa nacidos entre 1953 y 1967.

b) Generación de 1974. Un guarda de seguridad y una abogada nacidos entre 1968 y 1982.

c) Generación de 1989. 11 personas nacidas entre 1983 y 1997. 3 hombres y 8 mujeres. De ellas, por profesiones: 1 abogada, 1 profesora, 1 administrativa, 1 
El impacto de la publicidad en los hábitos alimenticios de los españoles: una cuestión de educación alimentaria

contable, 1 encargada de vuelos, 1 periodista, 1 cuidadora, 1 técnico y una desempleada. Él es taquillero.

La muestra proviene de estatus sociales claramente diferenciados ( 7 alto, 7 medio y 1 bajo) y formación heterogénea (7 licenciados, 6 con estudios de Formación Profesional Superior, 1 con los estudios de Bachillerato y 1 ama de casa con los estudios de Primaria).

\subsection{Instrumento}

Se han realizado dos entrevistas en profundidad diferentes. La primera de ellas, que consta de 11 preguntas (ver 3. Resultados), va dirigida a los 15 ciudadanos de a pie anteriormente descritos a modo de muestra significativa de una parte de la opinión pública. La segunda, por su parte, consta de 8 preguntas (ver 3. Resultados) y va dirigida a uno de los principales referentes del mundo de la nutrición y la dietética a nivel europeo (Dr. Tinahones).

Debido a la naturaleza del estudio y la metodología utilizadas, todas las preguntas y respuestas son abiertas, lo cual permite que cada entrevistado ofrezca su punto de vista. Cabe destacar que todos los participantes se comprometieron a responder con sinceridad antes de realizarles la entrevista.

\subsection{Procedimiento}

A los primeros 15 entrevistados se les hizo la entrevista de forma personal a cada uno de ellos por separado. En el caso del Dr. Tinahones, la entrevista se realizó vía telefónica por encontrarse en el hospital donde trabaja habitualmente (Málaga). Todos ellos eran conocedores de los temas que se iban a abordar en las entrevistas.

\subsection{Análisis de datos}

Las variables que se han tenido en cuenta son:

- Pertenecen a tres generaciones históricas diferentes.

- Son hombres y mujeres.

- En lo que respecta a su formación, van desde la Educación Primaria hasta titulados universitarios, pasando por bachilleres y técnicos de Formación Profesional.

- En relación a sus ocupaciones profesiones, hay desde profesionales liberales (abogada) hasta funcionarios de carrera (profesor), además de técnicos, altos ejecutivos y una desempleada.

La población de la muestra cumple con las variables del diseño del estudio. 
El impacto de la publicidad en los hábitos alimenticios de los españoles: una cuestión de educación alimentaria

\section{RESULTADOS}

Los resultados se presentan diferenciando, por un lado, las respuestas de los 15 consumidores y, por otro, las correspondientes al experto en nutrición.

a) Consumidores

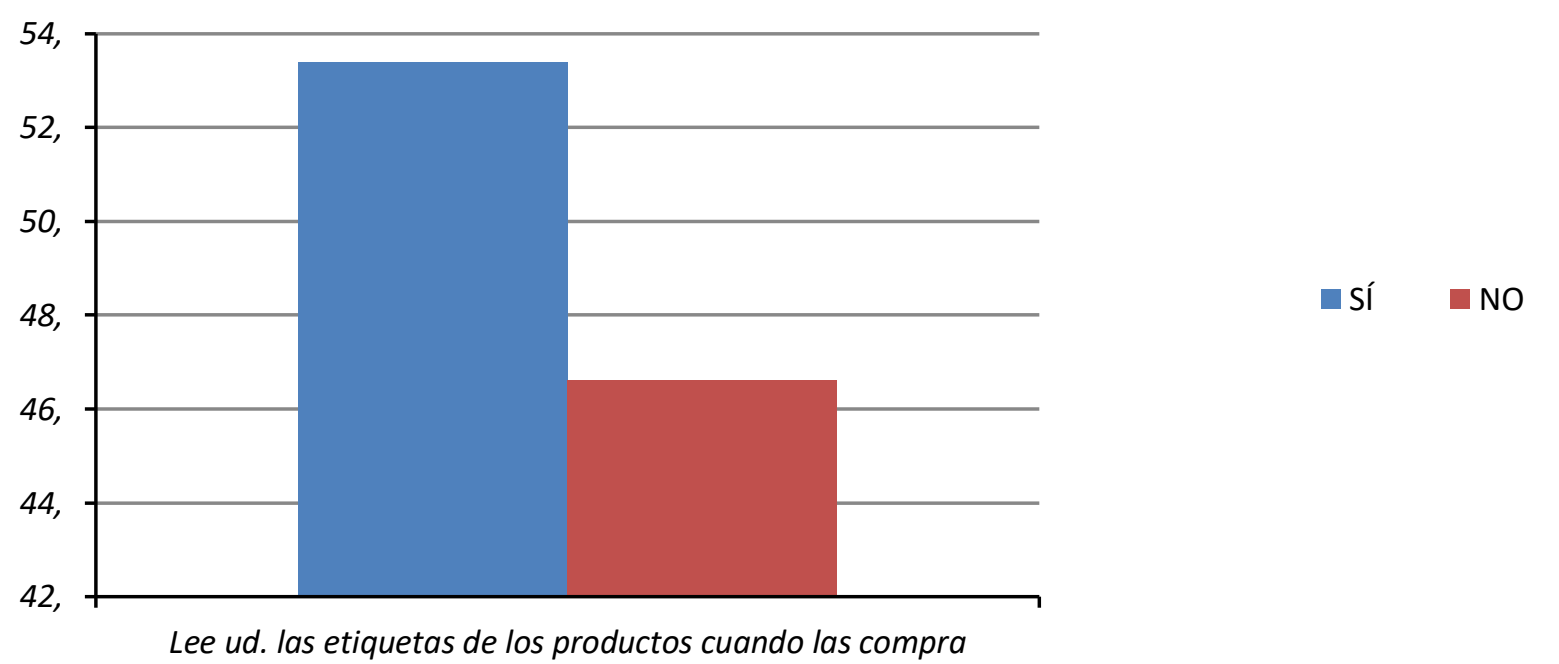

Grafico 1. ¿Lee usted las etiquetas de los productos cuando los compra?

7 respondieron no, que representa al $46,6 \%$ de los entrevistados, y 8 dijeron que sí, el $53,4 \%$. Por generaciones:

Generación de 1960. Ambos consumidores respondieron que no. En este subgrupo, ni el nivel de estudios ni el estatus profesional son relevantes. Resulta significativa esa coincidencia si se analizan las respuestas coincidentes de ambos si solamente se hace una interpretación superficial. Cuando, por un lado, dejamos el estereotipado marco analítico de las encuestas en los últimos sesenta años, claramente marcadas por un sesgo marxista con profundas lagunas científicas, observamos lo que demostró Ortega en La rebelión de las masas: una persona puede ser una autoridad en su campo, y a su vez un ser masa en otro en el que se considera igual de relevante su autoridad intelectual. La no lectura de las etiquetas de los productos alimenticios refleja el desconocimiento de una rica cultura educativa alimentaria, y el dejarse guiar por patrones alimenticios heredados que no puestos en cuestión.

Generación de 1974. En este segundo subgrupo, sin embargo, el nivel de formación y el desempeño profesional sí son relevantes y clarificadores, puesto que la profesional de la abogacía a diferencia del otro encuestado, sí muestra una mayor sensibilización y preocupación por los componentes nutritivos de los productos alimenticios que consume a diario. Esto quiere decir, que sí lleva tiempo centrándose en observar y conocer qué alimentos son mejores para la dieta de su persona y de su familia, con el propósito de 
El impacto de la publicidad en los hábitos alimenticios de los españoles: una cuestión de educación alimentaria

evitar patologías cardiovasculares, digestivas o de dificultades de movilidad como consecuencia del sobrepeso o la obesidad. En cambio, en el encuestado, se aprecia un problema que puede afectarle desde el corto al largo plazo: el desempeño de su profesión como guardia de seguridad se caracteriza, entre otros contextos, por un excesivo sedentarismo. Por tanto, tiene más riesgos de padecer a largo plazo patologías asociadas a una dieta alimentaria empobrecida como consecuencia de no haber desarrollado aún un hábito de lectura de los componentes de los alimentos de su cesta de la compra.

Generación de 1989. 6 contestaron que sí miran las etiquetas y 5 dijeron que no. Cuando se analiza las diferencias en este tercer subgrupo, de nuevo se coteja la evidencia científica de Ortega: hay licenciados universitarios que muestran una grave laguna en su formación dietética, alimentaria y nutricional. Dado que se trata de la generación más joven, también se constata otra máxima orteguiana: a una época de avances, de mejora de las condiciones de vida, no le tiene que proseguir otra que mejores incluso más los estándares de vida. De hecho, en los estudios nacionales y europeos de los últimos años se ha constatado que los menores españoles han pasado en la generación del Baby boom los que mejores ratios de calidad alimentaria tenían de Europa y los que menos sufrían las comorbilidades de la obesidad y el sobrepeso. A ser precisamente los miembros de esta generación de 1989 y la que viene detrás de ella (Generación de 2004), los que lideran las clasificaciones europeas en sobrepeso y obesidad.

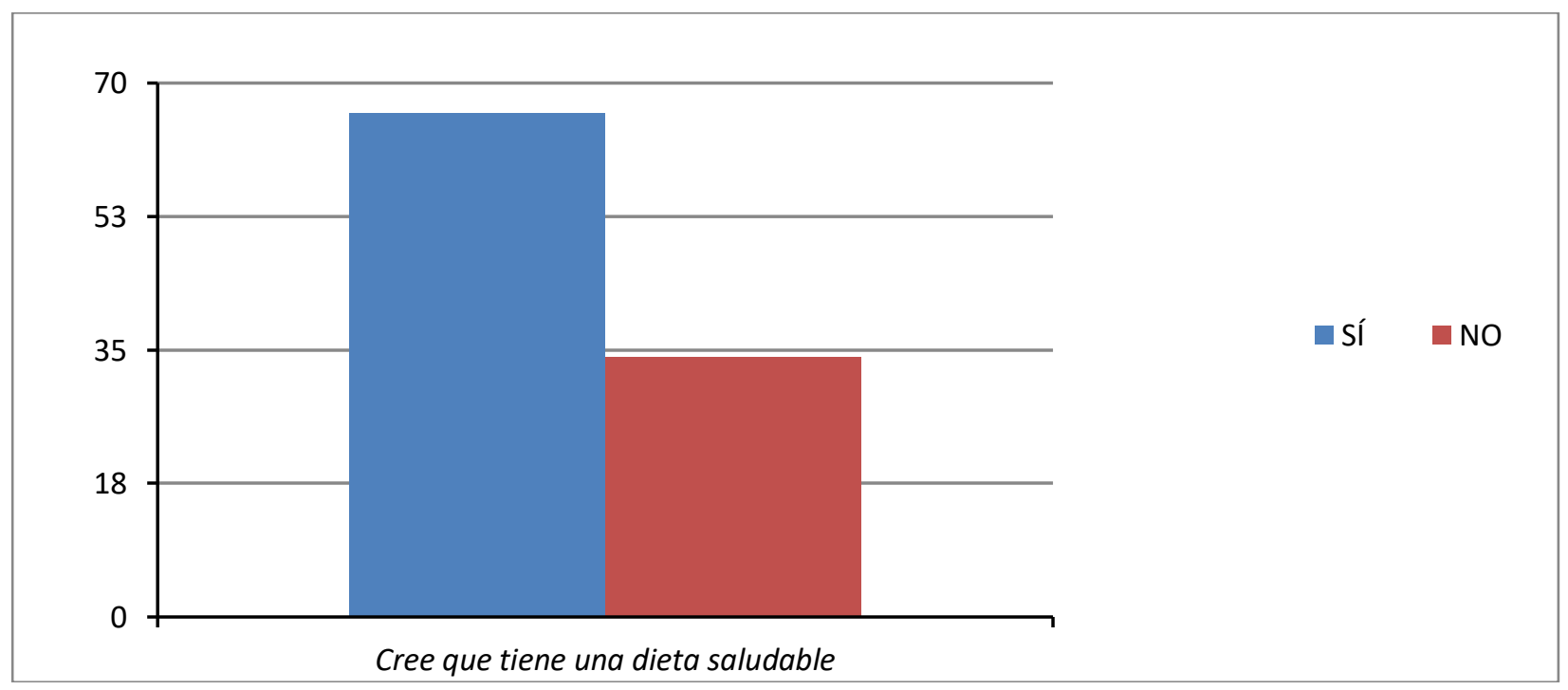

Grafico 2. ¿Cree que tiene una dieta saludable?

El 66\% afirmó que sí y el 34\% respondió que no. Por generaciones:

Generación de 1960. Coincide en que sí. Sin embargo, estas respuestas están basadas más en un desideratum que en una evidencia científica. Al cuestionarles a ambos sobre su estado de salud, se coteja que ambos presentan cuando no han 
El impacto de la publicidad en los hábitos alimenticios de los españoles: una cuestión de educación alimentaria

alcanzado los setenta años problemas de movilidad y de tensión alta asociadas ambas patologías clínicas a sus hábitos alimenticios y a la falta del suficiente ejercicio físico.

Generación de 1974. Quienes han respondido que no, reflejan un universo más diversificado. Aquí se aprecia otra vez que el estatus profesional y el nivel de estudios alcanzado no son determinantes. Hay dos tendencias de opinión y de prácticas alimentarias diferenciadas con claridad. Se confirma que solo 4 de los encuestados sí se preocupan por llevar una dieta saludable; mientras que los restantes reconocen tener un estilo de vida desordenado en el que están descuidando sus hábitos culinarios. A diferencia de la generación previa, la de 1960, aquí las tendencias sí están más repartidas. Hay miembros que sí se preocupan en su día a día de practicar una dieta saludable; mientras que los otros se dejan llevar por una cultura alimenticia o bien deficiente porque ya la tenían en sus hogares familiares de origen; o bien porque han caído en usos alimenticios perniciosos y han abandonado la cuidada dieta alimentaria que habían aprendido de sus mayores.

Generación de 1989. 5 no practican una dieta sana y 6 sí llevan una dieta saludable. En este subgrupo como en el anterior, hay dos corrientes de costumbres alimenticias marcadas. Lo significativo en este subgrupo, a diferencia del anterior, es que si asociamos las respuestas de unos y otros con las que dieron a la primera cuestión que se les formuló, sí se halla una correlación manifiesta y, por tanto, se puede extraer una conclusión científica: las personas que sí miran las etiquetas de los alimentos de su cesta de la compra tienden a llevar a una dieta saludable; mientras que quienes no lo hacen están empobreciendo no solo su alimentación diaria sino estropeando a medio y largo plazo su estado de salud.

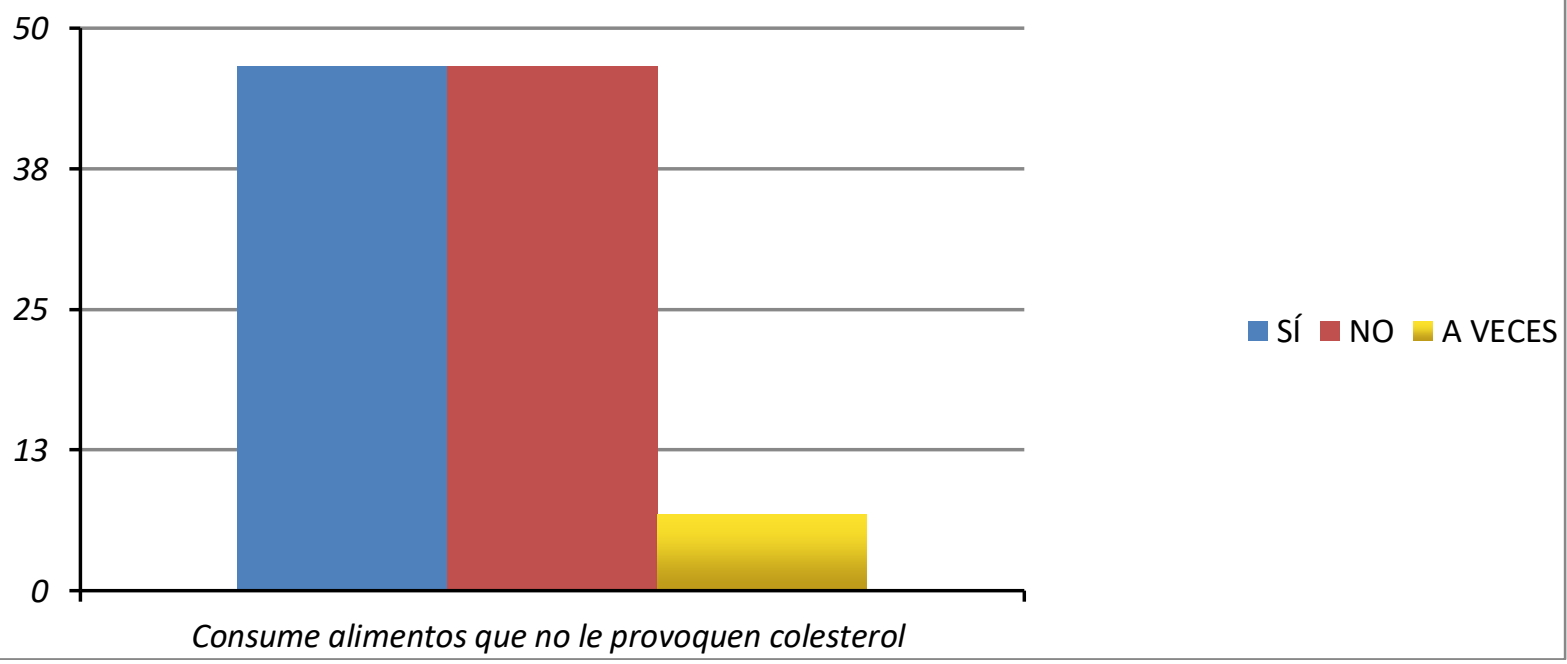

Grafico 3. ¿Decide usted qué compra viendo los ingredientes que tienen los productos?

7 contestaron que sí, 7 respondieron que no y 1 a veces. Por tanto, el $46,6 \%$ de la muestra afirma que sí. Otro 46,6\% afirma que no. Y, el 6,8\% que a veces. 
El impacto de la publicidad en los hábitos alimenticios de los españoles: una cuestión de educación alimentaria

Estas respuestas introducen en los tres subgrupos unos matices cuyo análisis detallado va a mostrar una serie de situaciones en unos casos paradójicas, y en otros en línea con las respuestas dadas de forma coherente a las dos primeras interrogantes que se les planteó.

Los matices paradójicos se encuentran tanto en los dos miembros de la Generación de 1960 como en los subgrupos de las generaciones de 1974 y 1989. En el caso del subgrupo de la generación de 1960 se da la particularidad de que comparten el hogar familiar porque están casados. Aquí se abre una línea de interpretación peculiar: la ama de casa, estatus vinculado históricamente a una figura docta en las labores propias del hogar, una de ellas la compra de los alimentos y su cocinado, sin embargo no se preocupa cuando realiza aquélla de comprobar la idoneidad de los ingredientes de los productos adquiridos. A diferencia de él que sí dice cotejarlos. En este sentido, su mayor nivel de formación y su profesión más reconocida a nivel social, parecen ser los elementos decisivos que explican su comportamiento opuesto. Lo que no deja de llevar a plantear una pregunta que al menos debiera ser inquietante para ambos de cara a su salud presente y futura: ¿serán capaces de modificar ese uso siguiendo el nuevo hábito de compra de él?, dado que resulta ser más saludable.

La paradoja se da también dentro de la generación de 1974, ya que solo hay una persona que sí tiene en cuenta los componentes de los productos alimenticios que compra. El resto afirma no tenerlos presentes a la hora de hacer la cesta de la compra. Esto introduce una nueva realidad que cuestiona las respuestas que dieron a la segunda pregunta, en la que afirmaron que sí llevan una dieta saludable. ¿Hasta qué punto es esto real? ¿No miran a menudo los componentes de los productos que ingieren porque los conocen en profundidad y saben ya que son saludables?

En el caso concreto de una de las participantes, la abogada de 33 años, sus respuestas muestran con claridad la vida desordenada y empobrecida en hábitos alimenticios que está practicando. Ya que, por un lado, afirma que sí mira los ingredientes de los productos que compra y, en cambio, en la pregunta anterior contestara que no lleva una dieta saludable (compra alimentos muy grasos y con azúcares). Por tanto, de poco le sirve la lectura de las etiquetas porque está ingiriendo productos que empobrecen su dieta cotidiana y su salud.

Las respuestas en línea y coherentes con las que dieron a la disyuntiva previa, se observan entre seis personas de la generación de 1989 que basan su cesta de la compra en alimentos frescos. 
El impacto de la publicidad en los hábitos alimenticios de los españoles: una cuestión de educación alimentaria

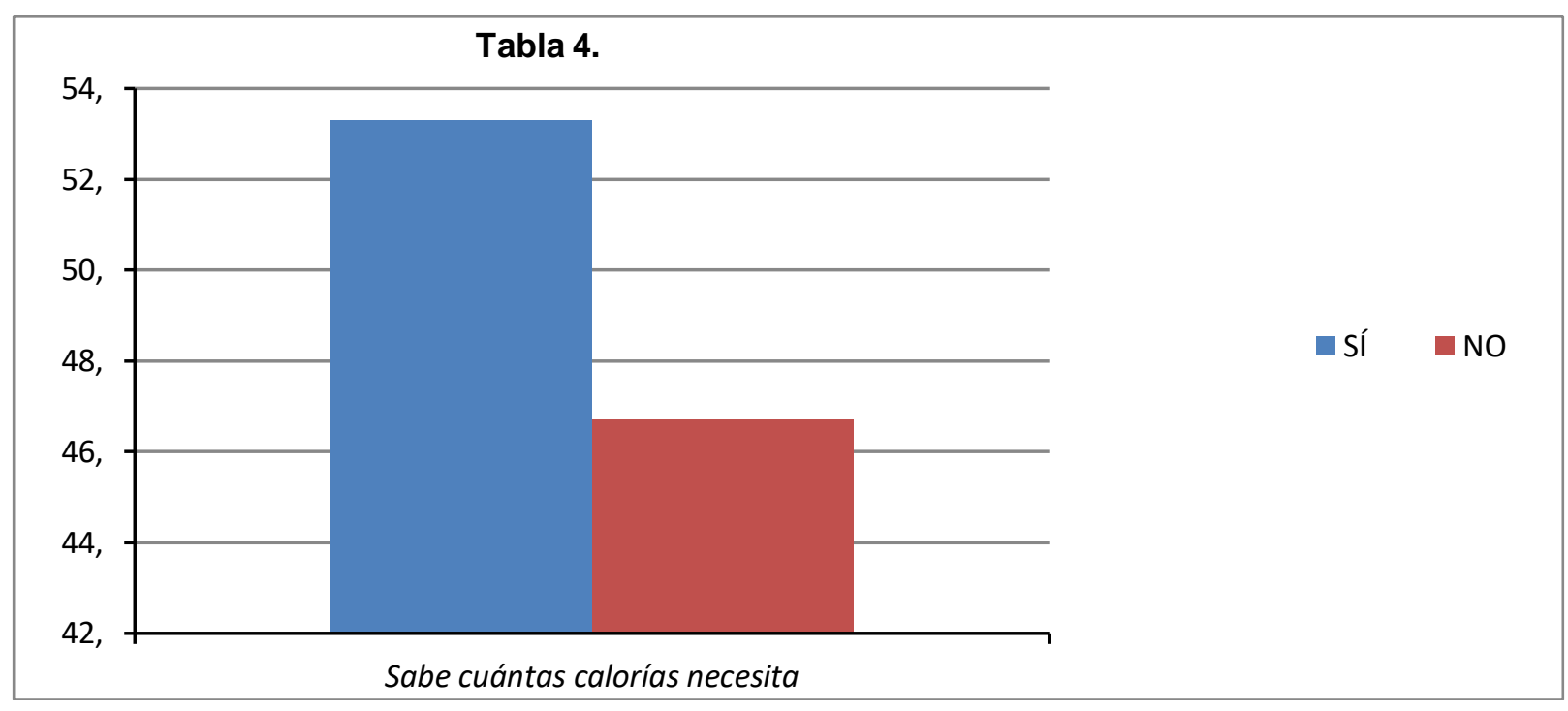

Grafico 4. ¿Sabe cuántas calorías necesita?

8 respondieron que entre 2.000 y $2.500 \mathrm{kcal}$. Ellos representan al $53,3 \%$ de la muestra. Esta cuestión introduce una nueva realidad: el desconocimiento agudizado que se manifiesta en buena parte de los encuestados sobre cuántas calorías requiere a diario en función de la vida que lleva. Aquí hay dos subgrupos que se identifican con claridad: Uno, el que forman 8 encuestados que son conscientes de que necesitan ingerir entre 2.200 y $2.500 \mathrm{kcal}$ diarias para hacer frente a su estilo de vida.

Y el otro subgrupo, formado por 7 encuestados que desconocen cuántas kilo calorías requieren para hacer frente a sus necesidades vitales cotidianas. Ellos son el $46,7 \%$ de los entrevistados. Con el agravante en este subgrupo de que 2 de las personas encuestadas manifiestan un profundo desconocimiento de las kcal diarias que necesitan consumir, estando en uno de los casos (la administrativa) en la mitad de la ingesta que requiere. $Y$ en el supuesto de la asistente de ventas, manifiesta que necesita una tercera parte de kcal de las que en realidad demanda su estilo de vida. En sus casos, ambas de seguir ese ritmo de vida y esa empobrecida dieta alimenticia pueden padecer enfermedades graves como la anorexia. 
El impacto de la publicidad en los hábitos alimenticios de los españoles: una cuestión de educación alimentaria

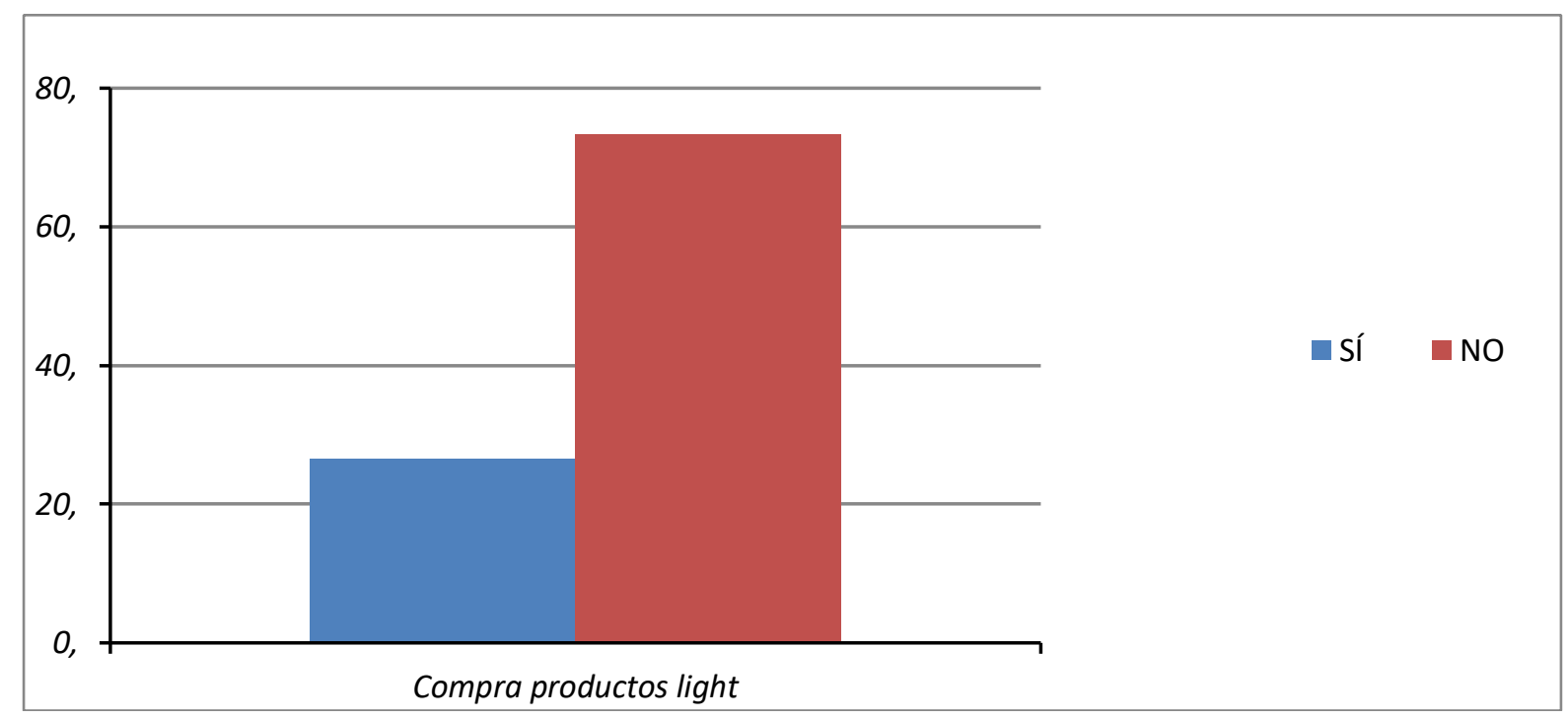

Grafico 5. ¿Compra productos light? ¿Por qué?

El $73,4 \%$ de los entrevistados no compra ni consume productos light. Los motivos que dan para esa decisión van desde quien los considera un engaño hasta la mayoría de quienes no los adquieren porque no les gustan y prefieren los productos frescos. Se deduce de las contestaciones de estas personas, por un lado, que han elegido para su dieta alimentaria los ya citados productos frescos, en consonancia con una dieta propia de la cultura mediterránea. Y, por otro, resulta muy significativa la opción del entrevistado que directamente considera "un engaño" los productos light.

Lo que llama la atención de su hábito y de su elección es que forma una unidad familiar junto a dos de las también encuestadas (su esposa y una hija). Y solo es la esposa quien en ocasiones los compra y consume.

El resto, 4 de los encuestados, que representa el 26,6 de la muestra, dentro de su cesta de la compra sí optan por productos que están dentro del segmento de los denominados light. Entre las razones que esgrimen para ese hábito señalan tres: una, les gustan. Dos, opinan que son más saludables. Tres, porque si es verdad lo que indican las etiquetas de esos productos, en teoría tienen menos grasas saturadas. Como conclusión deducen que la catalogación de light la asocian a "comer más sano".

Por las respuestas de los 15 entrevistados se aprecia con claridad que no son la edad ni la generación las circunstancias decisivas. Están más influidos por los hábitos alimenticios de cada uno y por las ideas que tienen de esos alimentos. 
El impacto de la publicidad en los hábitos alimenticios de los españoles: una cuestión de educación alimentaria

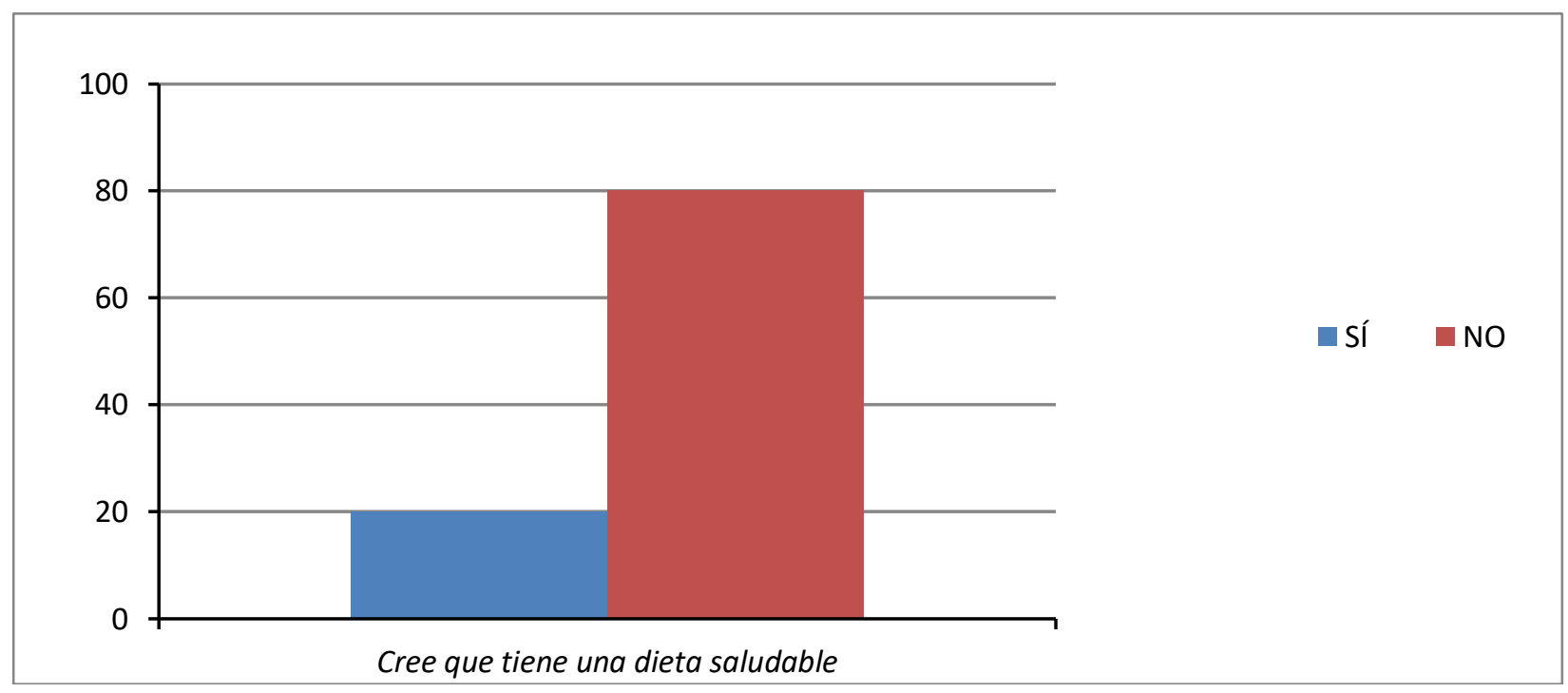

Grafico 6. ¿Sabe cuál es el porcentaje de azúcar que consume a diario y cuál es la cantidad saludable?

El $80 \%$ de los entrevistados desconoce tanto la cantidad de azúcar diaria que consume como cuál es el volumen que debiera tomar en función de sus características fisiológicas, de su modus vivendi, y de las patologías que o bien alguno ya tiene o se les van presentando sin ser aquéllas graves a día de hoy ni tampoco sufrir ninguno de ellos patologías crónicas. Reconocen que no es una cuestión que se paren a pensar en su día a día.

Una de las particularidades que se ha detectado al entrevistarlos, es que dentro de ese $80 \%$ de entrevistados, hay quienes afirman que solamente toman los azúcares propios que tienen los alimentos frescos. Por tanto, que no consumen otro tipo de alimentos hechos o fabricados con aditamentos industriales.

Por último, el $20 \%$ que sí afirma saber la cantidad de azúcar que consume en su día a día, pero en cambio reconoce que desconoce cuál sería la cantidad saludable que debiera ingerir. ¿En qué tipo alimentos o bebidas consumen esos azúcares? Consumen azúcares cuando toman cafés, o recurren a productos industriales como tomate frito, pan industrial, dulces, galletas o ciertas bebidas como los refrescos.

En estas dos interrogantes, se observa que ni la generación ni la edad son circunstancias determinantes en esos hábitos alimenticios concretos. Están más ligados a unos hábitos y gustos en su día a día. Dado que la ingesta de azúcares industriales no es sana, como demuestran estudios clínicos internacionales (aunque no se este el objeto de este artículo), sí ha llevado a algunos de los entrevistados a detenerse a pensar en practicar cambios en su dieta alimenticia. 
El impacto de la publicidad en los hábitos alimenticios de los españoles: una cuestión de educación alimentaria

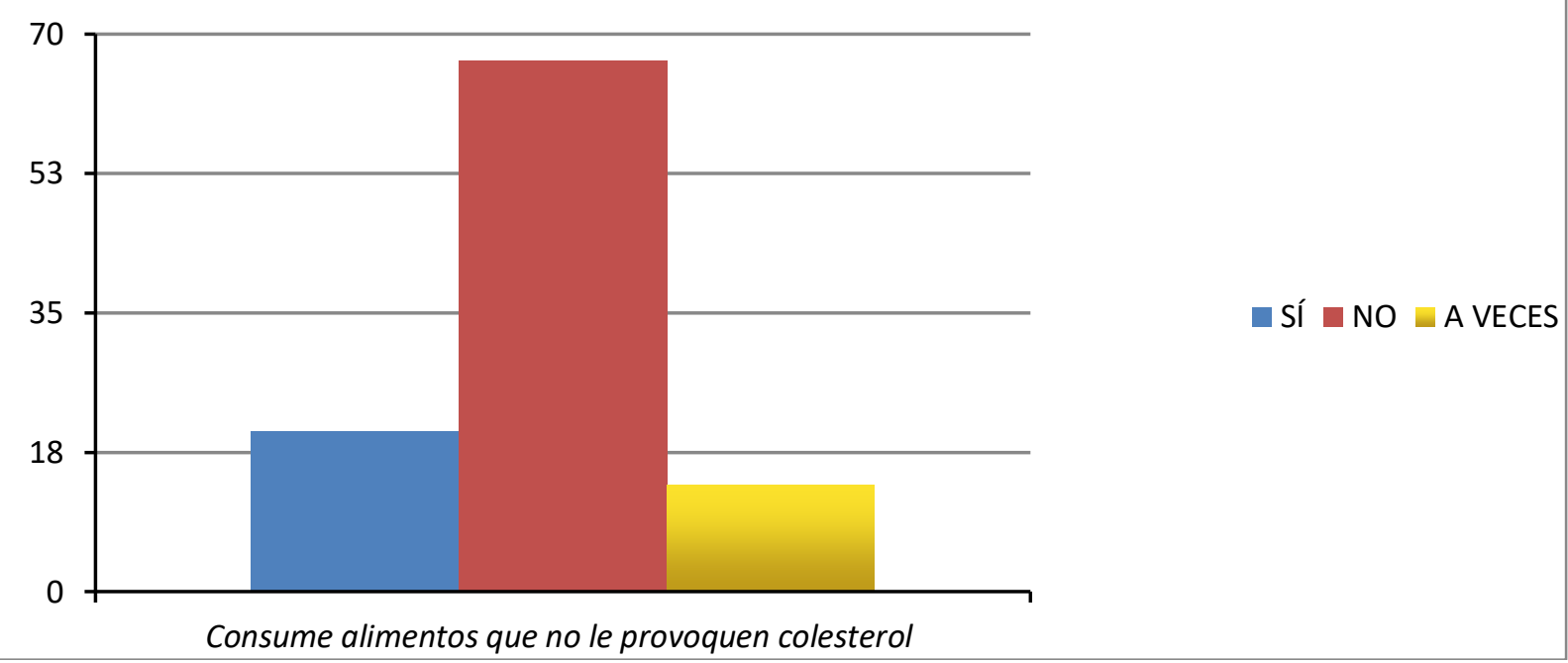

Grafico 7. ¿Consume alimentos que no le provoquen colesterol u otros para regular su tránsito intestinal? ¿Nota los resultados?

Hay tres subgrupos que se diferencian con claridad. Uno, lo forma el $66,6 \%$ de los entrevistados que no toman alimentos específicos que provoquen colesterol o que sirvan para regular el tránsito intestinal. ¿A qué se debe esto? A que no creen ni en los productos específicos para controlar el colesterol ni tampoco en aquellos recomendados para mejorar el tránsito intestinal. Y solo uno de ellos reconoce tomar de vez en cuando Danacol pero desconoce si es eficaz o no contra el colesterol como se dice en sus campañas publicitarias y en la etiqueta de su envase. Resulta llamativo que todos los que han dicho que no pertenecen a la generación de 1989, salvo una integrante de la generación de 1974. De esto se puede deducir que son los miembros de la generación más joven entrevistada la menos o nada proclive a este tipo de productos.

El segundo grupo lo integran los que sí los consumen y que representan al $20 \%$ de los entrevistados. Se da la circunstancia de que 2 de los 3 que sí los ingieren pertenecen a la generación de 1960. Este dato sí es ilustrativo porque es una generación que se crío en su niñez y adolescencia con una cultura alimenticia en el que el consumo de los productos lácteos fue relevante. Téngase presente que es la primera generación en España que creció durante la posguerra de la Guerra Civil española de 1936. También que esa generación ya en edad adulta es la que presenta entre sus miembros unas tasas de colesterol más preocupantes, provocando en ellos, como los estudios al respecto demuestran, patologías que afectan a sus vidas diarias y que van desde las más suaves o que han podido superar a otras graves o crónicas, y en el peor de los casos hasta causarles comorbilidades que han desembocado en la muerte. Es asimismo significativo de los hábitos alimenticios de quienes sí los consumen, que hay un entrevistado que solo se alimenta de productos frescos y ricos en fibras naturales que no suben los niveles de colesterol y le regulan su flora intestinal. Mientras que las otras dos entrevistadas que contestaron que sí, además de tomar alimentos frescos y naturales, también consumen 
El impacto de la publicidad en los hábitos alimenticios de los españoles: una cuestión de educación alimentaria

alimentos y bebidas recomendados por sus fabricantes para controlar el colesterol o mejorar su flujo intestinal.

El tercer subgrupo, que representa al $13,4 \%$ de los entrevistados, reconoce que "a veces" toma productos para controlar los niveles de colesterol o para mejorar la flora intestinal. Ambas afirman que "si" les ha calado el mensaje de las campañas publicitarias, y que por eso ingieren productos tipo Activia.

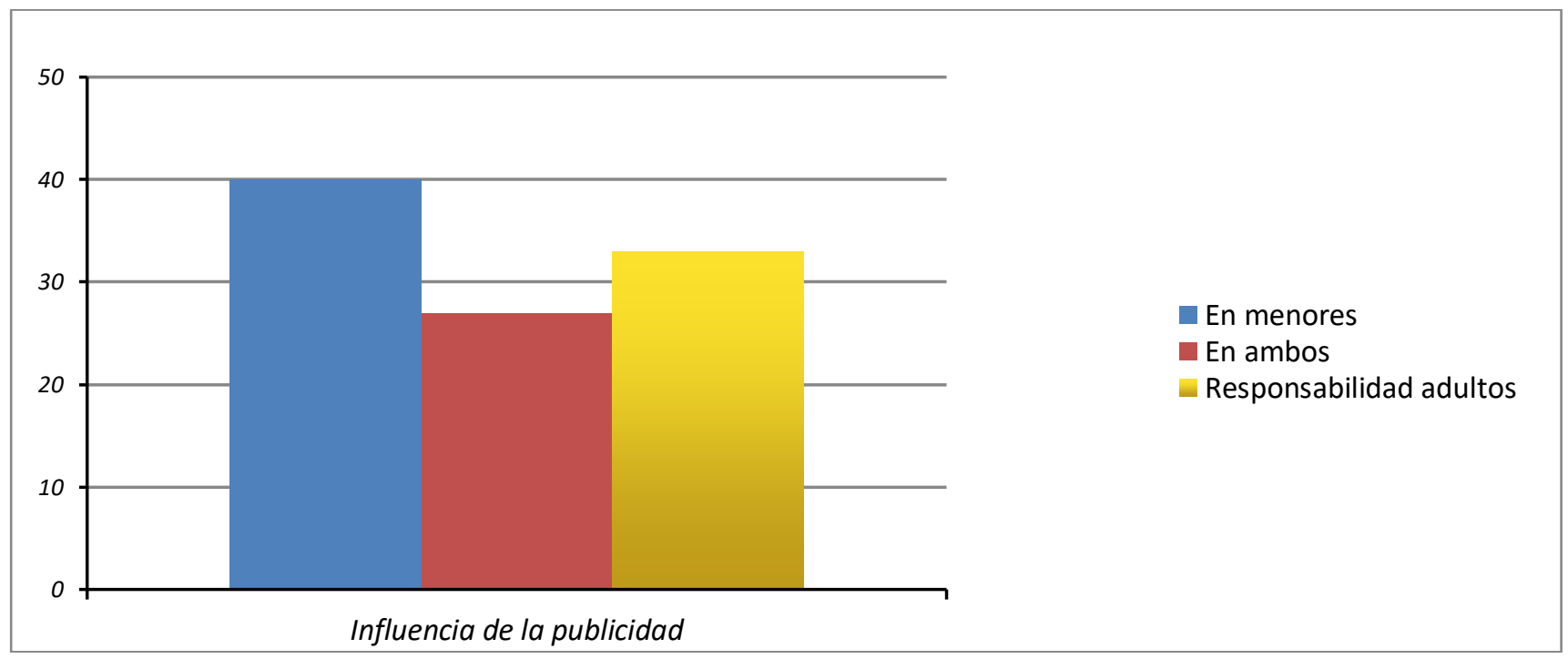

Grafico 8. ¿Cree que la publicidad en los alimentos influye más en los menores que en las personas adultas? ¿Qué matices significativos introducen?

Hay tres subgrupos. El primero lo forman quienes consideran que la publicidad influye más en los menores, una visión compartida por miembros de las tres generaciones entrevistadas. Representan al $40 \%$ de los entrevistados. Dentro de este grupo de opinión se encuentran posiciones matizadas, desde quien considera que ya existen suficientes leyes que regulan los espacios publicitarios de la industria alimentaria hasta quien propone que haya más leyes y pone el énfasis en la responsabilidad de los padres que son quienes hacen la compra. Todos abogan por desarrollar más legislación que proteja a los menores y, sobre todo, en que haya cambios drásticos en los contenidos televisivos dedicados a los niños y adolescentes. Esto último lleva acarreada la propuesta de adoptar medidas que van desde la eliminación de aquellos recursos del marketing que estimulan los deseos de compra a los menores de productos nocivos hasta la prohibición de cierto tipo de anuncios. O bien, que se regulen las franjas horarias televisivas de los espacios publicitarios que estimulan el consumo de dulces industriales. Estas posiciones se fundamentan en los datos científicos sobre el excesivo consumo de bollería con azúcares añadidos.

Integran el segundo subgrupo 4 entrevistados, que son el $27 \%$ de la muestra. Para ellos, la publicidad influye en adultos y menores. Éstos participantes en la investigación pertenecen a las generaciones de 1960 y 1974. Entre ellos, todos coinciden en la 
El impacto de la publicidad en los hábitos alimenticios de los españoles: una cuestión de educación alimentaria

necesidad de regular los espacios publicitarios dirigidos tanto a menores como adultos. En este sentido, apuestan por dos líneas de actuación concretas: Una, introducir nueva normativa (algo que también propone el primer subgrupo analizado). Dos, exigir a las entidades públicas que tienen la autoridad de velar por la Salud Pública que mejoren el ejercicio de sus funciones y competencias, y que dispongan también de más medios para llevarlo a cabo.

Componen el tercer subgrupo el $33 \%$ de los entrevistados. Todos pertenecen a la generación de 1989. Para ellos, la responsabilidad principal está en los padres y en las madres de los menores. Han de ser ellos quienes, por un lado, establezcan los menús alimenticios que toman sus descendientes a diario, y tengan una dieta saludable basada en comer productos frescos en lugar de los precocinados difundidos en determinadas campañas publicitarias. Y, por otro, controlar también las familias dentro de lo posible los contenidos televisivos que consumen los menores: tanto las campañas publicitarias que se insertan entre esos contenidos, como la propaganda tipo product placement en las propias series de televisión (se promocionan bebidas, comida rápida, etc. dentro del propio capítulo o película).

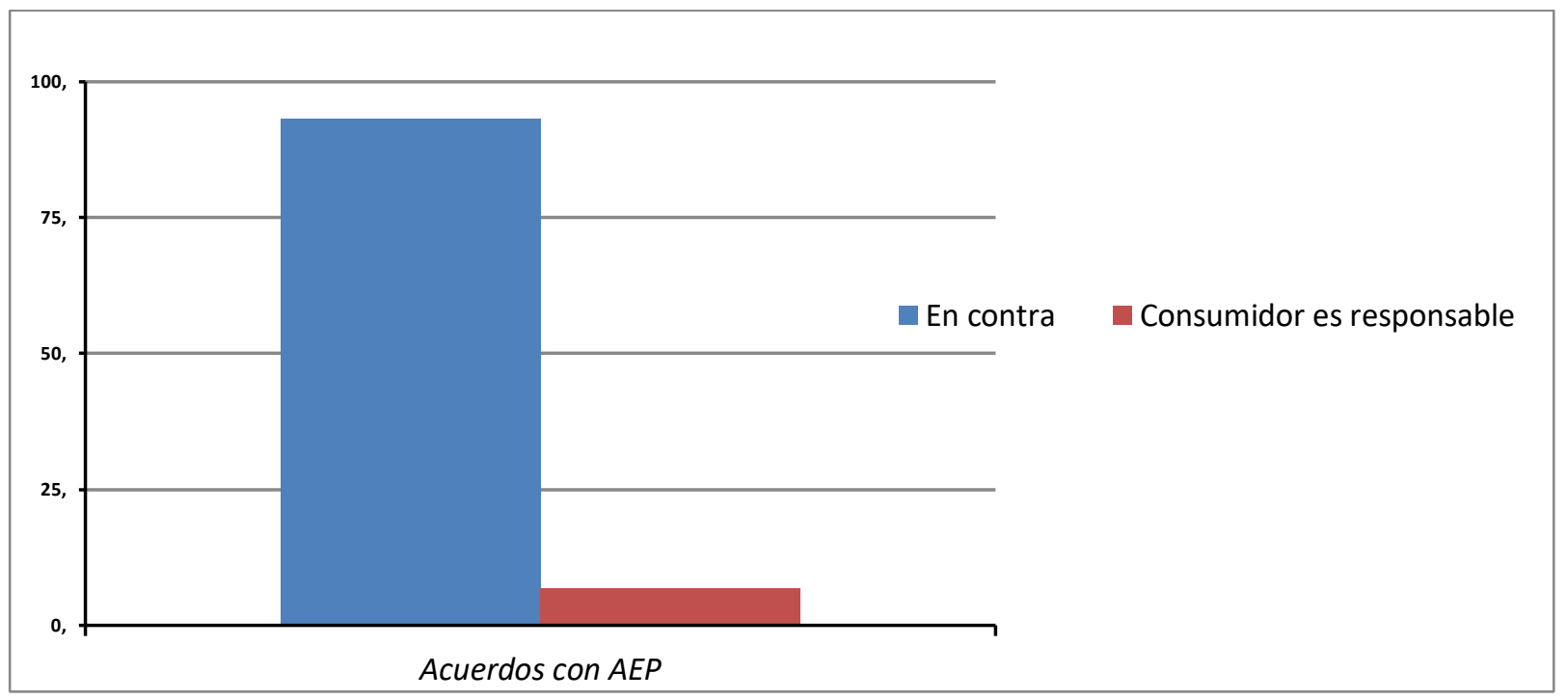

Grafico 9. ¿Qué opina del acuerdo de la Asociación Española de Pediatría (AEP) con empresas que venden productos con mucha grasa y azúcar para niños? ¿Qué alternativas proponen?

14 de los 15 entrevistados están en contra de ese acuerdo entre la AEP y las compañías que comercializan esos productos, son el 93,3\% de los entrevistados. Entre las propuestas que hacen, destacan: impedir que el lobby de la industria alimentaria haga lo que quiera y, además, cuente para ello con el respaldo de las autoridades sanitarias. Prohibir la fabricación y el consumo de esos productos que están provocando sobrepeso y obesidad en los menores españoles. Además, defienden que se fomente la práctica cotidiana del deporte entre adultos y niños. Piden que se exija a los pediatras que recomiendan esos productos, que rectifiquen y cumplan con su Código Deontológico. En 
El impacto de la publicidad en los hábitos alimenticios de los españoles: una cuestión de educación alimentaria

caso contrario, que sean sancionados desde con una multa económica hasta con otras sanciones más graves. Que se impida la comercialización de productos, en teoría, saludables y con etiqueta azul, que en realidad no lo son. Defienden la vuelta a la dieta mediterránea sustentada en alimentos frescos y de temporada. Obligar a esas empresas fabricantes de productos industriales a bajar la cantidad de azúcares y grasas saturadas, o bien a que paguen más impuestos por esos productos. Se pide aplicar una misma norma en todos los colegios de España promoviendo el consumo de productos frescos.

La excepción de los entrevistados es una de las entrevistadas, que representa al 6,7\% de la muestra. Para ella, la responsabilidad principal en la toma de decisiones está en la gente que se deja por dejarse seducir o engañar por la publicidad.

Desde un plano científico, los autores de este artículo sugieren, por un lado, introducir todas las objeciones formuladas por el primer subgrupo de entrevistados. Y, por otro, es obvio que cada persona o familia es corresponsable de su cesta de la compra.

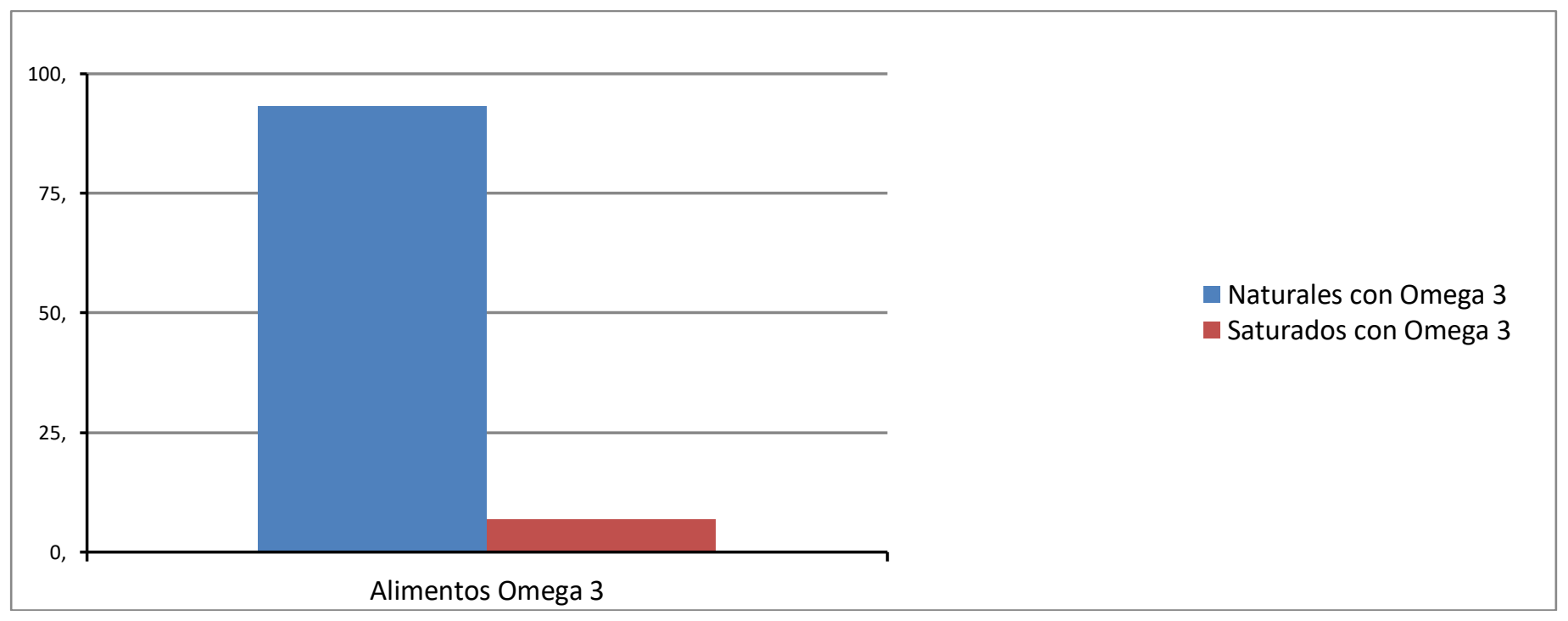

Grafico 10. ¿Cree que los alimentos "con vitaminas, omega 3» son los mismos que otros que los contienen de forma natural?

El $93,3 \%$ de los entrevistados prefiere los alimentos naturales que ya contienen esas vitaminas y propiedades en lugar de los suplementos vitamínicos.

Además, aportan matices en sus respuestas, desde aquellos que se muestran muy duros con los productos que los incorporan de forma industrial o química, en concreto el $46,65 \%$ prefiere no consumir productos que incorporen esas vitaminas a través de procesos industriales. Y al otro $46,65 \%$ que no les importa que haya compañías que en sus productos incorporen vitaminas o ácidos grasos tipo Omega 3 . En este segundo grupo se propone que las compañías informen a los consumidores del porcentaje mínimo de omega 3 , de vitaminas o calcio que llevan incorporados sus productos. 
El impacto de la publicidad en los hábitos alimenticios de los españoles: una cuestión de educación alimentaria

El matiz diferenciador a esta cuestión queda representada por una entrevistada, que representa al $6,7 \%$ del total. Coincide con el resto de participantes y solo matiza que hay algunos productos procesados con esas vitaminas y suplementos que pueden ser más fáciles de encontrar y de consumir para el consumidor que los frescos que los llevan.

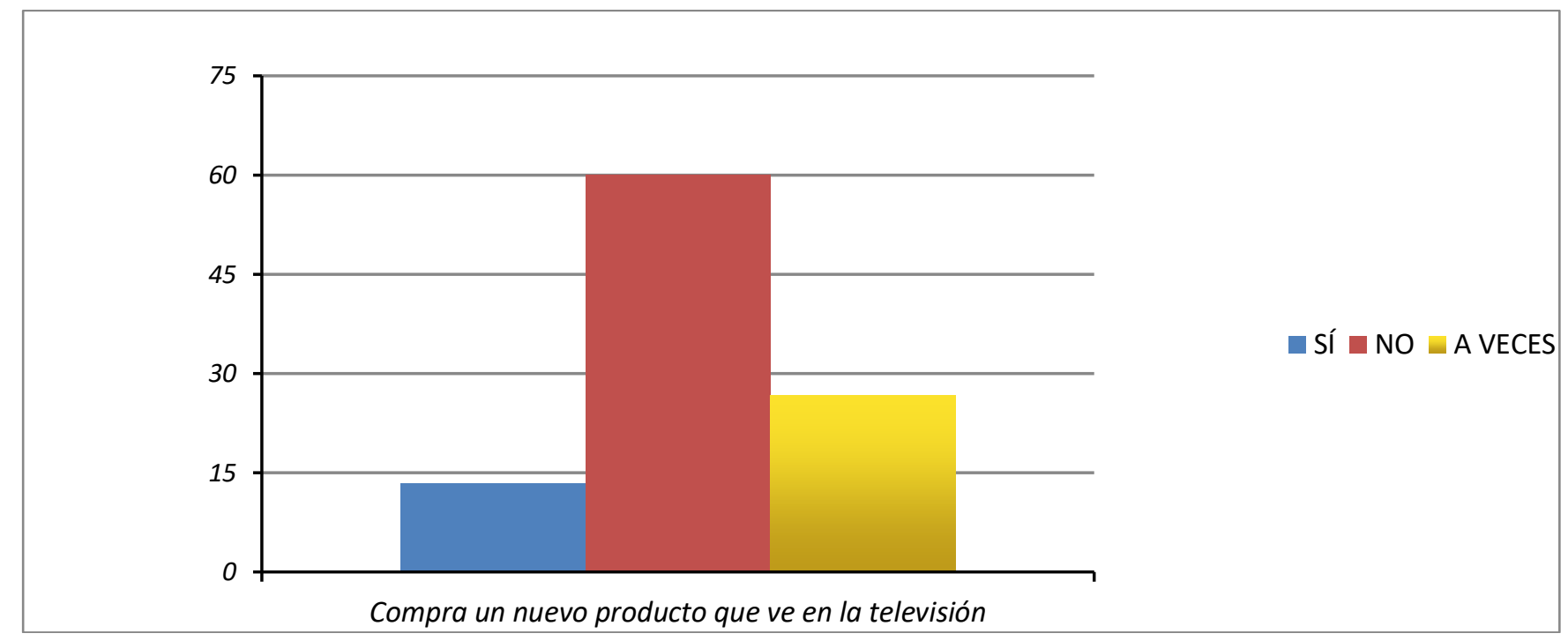

Grafico 11. ¿Compra un nuevo producto que ve en la televisión? ¿Influye la publicidad en sus decisiones?

El $60 \%$ de los entrevistados respondieron que no. Prefieren comprar productos frescos, de temporada y de calidad. Analizan los productos de su cesta de la compra para seguir adquiriéndolos donde lo hacen habitualmente; o en algunos supuestos cuando no cumplen con los estándares de calidad alimenticios que buscan, se han visto obligados a comprarlos en otros establecimientos de cercanía que sí les ofrecen esa calidad buscada. También son contrarios al aumento notable del precio de los alimentos de la cesta de la compra como consecuencia de la inversión en campañas publicitarias costosas. E incluso afirman que la visión principal de los contenidos televisivos a través de las plataformas tipo Netflix les posibilita no tener que consumir publicidad directa sobre alimentos. Aunque sí reconocen que de forma indirecta a través del product placement pueden estar recibiendo un impacto publicitario del que no eran conscientes cuando se les entrevistó.

El 26,7\% de los entrevistados respondieron "a veces". En sus casos se dejan influir por los anuncios de bollería industrial y de comida basura, despertándoles la publicidad en ocasiones el apetito como cuando, por ejemplo, visualizan un anuncio de una tarta.

Integran el último subgrupo dos de los entrevistados, que representan al $13,3 \%$ del total. Ambos reconocen que les influyen los anuncios publicitarios de productos alimenticios, pero cada vez menos, y afirman que tienden a realizar compras compulsivas. Esa mala praxis también la observan en mucha gente de su entorno. De 
El impacto de la publicidad en los hábitos alimenticios de los españoles: una cuestión de educación alimentaria

esto último se extrae que en ocasiones como esas el entorno social, su cultura alimenticia y el consumo mediático pueden actuar de forma negativa entre sus miembros.

\section{b) Experto en nutrición: Dr. Francisco Tinahones:}

I. ¿Qué piensa de los acuerdos que la Asociación Española de Pediatría tiene con marcas como Cuétara, Tostarica, Nestlé... que no tiene productos precisamente sanos, dirigidos a los niños?

Tendría que tener más información de qué implican esos acuerdos y las condiciones de los mismos. Sin esa información, no me atrevo a emitir un juicio.

II. ¿Qué opina sobre que en los colegios se hablara a los niños de nutrición y buenos hábitos alimenticios? ¿Serviría de algo o a los que verdaderamente habría que "educar "sería a los padres?

El trabajo con el niño es necesario en el ámbito escolar para incrementar la educación en hábitos saludables, pero en esas etapas es más importante la educación de los padres.

III. ¿Cree que gran parte de la culpa de las tasas de obesidad en España es culpa de esta falta de información sobre nutrición que tenemos? ¿Qué medidas sugeriría?

No solamente eso, la falta de información es importante pero no lo único. Las tasas de obesidad en los sanitarios son sólo discretamente inferiores a la población general, y estos profesionales tienen toda la información. Vivimos en un hábitat claramente obesogénico y habría que actuar a nivel multifactorial.

IV. ¿Cree que influye más la falta de formación en temas nutricionales o la influencia del excesivo marketing en los medios de comunicación?

El márketing.

V. ¿Cree que se debería poner alguna medida al intrusismo en el mundo sanitario?

El intrusismo en las recomendaciones nutricionales es descomunal. Igual que en cardiología nadie que tenga esa expertise se atreve a hacer recomendaciones, en nutrición todo el mundo se atreve (artistas, cocineros, etc.) y esto creó un enorme ruido de fondo que impide que lleguen mensajes claros basados en la evidencia científica.

VI. ¿Cómo piensa que afecta la no conciliación familiar respecto a la alimentación de los niños?

De una forma importante. 
El impacto de la publicidad en los hábitos alimenticios de los españoles: una cuestión de educación alimentaria

VII. Últimamente se ha hablado mucho de lo perjudicial que son los aditivos como el glutamato monosódico, qué papel cree que tienen en la «epidemia de obesidad" que vive España actualmente?

No existen evidencias para recomendar o prohibir su uso, hacen falta más estudios para tener una opinión.

\section{VIII. ¿Qué opina de los menús que se dan en hospitales a los enfermos? ¿Y los menús para niños en los colegios?}

Los menús en los hospitales están balanceados y aprobados por endocrinólogos o nutricionistas. En los colegios la situación es más variable.

\section{DISCUSIÓN Y CONCLUSIONES}

A la luz de los resultados expuestos, se puede concluir:

- El marketing de productos grasos y con azúcares añadidos está influyendo en el aumento del sobrepeso y de la obesidad entre los españoles. Esto enlaza con el objetivo general de este trabajo acerca de la necesidad de que haya una mejor información nutricional para crear una educación basada en hábitos saludables y, también, con el primer objetivo específico de lograr con ello una dieta sana. Para superar esto se hace imprescindible tomar una serie de medidas: Una, que las autoridades competentes responsables en velar por el cumplimiento de la salud pública impidan la publicidad y las campañas de marketing de aquellos alimentos o productos que provocan sobrepeso, obesidad y otras patologías. Dos, premiar desde las instituciones públicas a los medios de comunicación que deciden con el riesgo económico que ello conlleva, no dar cabida en sus espacios publicitarios o en los denominados publirreportajes a campañas que promocionen productos grasos y con azúcares añadidos. Tres, aunque desde hace años en centros escolares e institutos se están llevando campañas de educación alimentaria y nutricional de la mano de las Consejerías de Salud, profundizar en las mismas y dar explicaciones a los menores y a sus familiares qué alimentos están hechos con esos componentes nocivos para la salud y porqué han de ser eliminados de la dieta diaria. Cuarto, mediante reuniones y decisiones eficaces provocar en las empresas alimentarias que fabrican esas comidas, que dejen de hacerlo, y pasen a hacer y cocinar otras que sí sean sanas. Se trataría de fomentar una reconversión inteligente de una industria con malas praxis, con lo que ello implica de apostar por la salud pública y por la generación de empleo y riqueza sostenible.

- Acabar con el intrusismo en las recomendaciones dietéticas, que van desde la propaganda manipuladora de determinadas empresas alimenticias, hasta las opiniones sin fundamentos que vierten determinados profesionales ajenos a la medicina. De esta manera, se responde a otro de los objetivos específicos planteados: la información de las etiquetas alimenticias tienen que ser veraces. De nuevo, hemos de recurrir a Ortega y a su distinción entre persona noble y 
persona masa. Ya a la primera de ella se hizo referencia en la Introducción de este artículo (p. 3). La segunda es el reverso de la misma, es aquella que solo quiere derechos y no asume sus obligaciones. Ortega lo demostró en su célebre ensayo hace ya casi un siglo, recuérdese que se publicó en formato artículos periodísticos a partir de 1925 en el diario El Sol, y en formato libro desde 1927. E identificó al científico como el ejemplo máximo de la persona masa. ¿Por qué? Porque éste siendo una autoridad en su campo, se permitió la licencia de dar su punto de vista sobre cualquier asunto que desconocía y arrogándose la misma potestad. Hoy esto lo podemos ver en los medios de comunicación españoles cuando en determinados programas televisivos, tertulias radiofónicas o contenidos en formatos papel o digital se abordan cuestiones como hábitos alimenticios y nutricionales saludables sin cumplir con el rigor y el conocimiento requeridos por parte de quienes abordan esos asuntos.

- Hay que lograr la conciliación de la vida familiar y laboral porque está impidiendo que haya una cultura alimenticia y de hábitos de vida sanos. Esto como ya se avanzó en la Introducción está imposibilitando dedicar el tiempo, el diálogo y la práctica de buenos hábitos alimenticios en todas aquellas familias con graves dificultades para equilibrar su día a día profesional y personal. Como todo en la vida, los usos y las costumbres inteligentes radican en la capacidad de discernir entre varias posibilidades, son fruto de tomar decisiones a partir de sopesar los pros y contras de cada una de ellas. Cuando en el interior del hogar no se reservan unos tiempos y unos espacios para poner en práctica desde el silencio y la comunicación clara y educativa centrada en por qué hay que comer unos determinados alimentos y combinarlos con otros en cada una de las comidas diarias, y cuándo se puede hacer la excepción para ingerir ciertos caprichos, la base y el ejemplo que se ha de dar a las nuevas generaciones se quiebran desde el inicio. Está más que demostrado en cualquier campo que la mejor escuela de formación es aquella que se practica a diario desde el ejemplo y la coherencia. Si las generaciones más jóvenes no ven a sus mayores practicarlas, ellas no las practicarán (salvo casos aislados y dignos de elogio que los hay, y que en un esfuerzo titánico hacen lo opuesto a lo que ven en sus progenitores).

- No hay evidencias científicas claras que demuestren hoy que ciertos aditivos estén causando un aumento de la obesidad y, por tanto, haya que prohibirlos. De hecho, el estudio clínico denominado PREDIMED-Plus y realizado entre 6.874 adultos mayores con sobrepeso/obesidad y síndrome metabólico (Álvarez et al., 2019), a partir de la ingesta de una dieta mediterránea sin restricción de energía y suplementada con aceite de oliva virgen extra o una combinación de frutos secos logró reducir de forma notable el riesgo de un primer evento cardiovascular en el $30 \%$ de los participantes en el grupo de intervención comparado con un grupo de control al que se le propuso una dieta baja en grasas. En este sentido hemos de destacar el papel decisivo de las mujeres adultas porque son en buena medida las encargadas de hacer las compras de los alimentos y de cocinarlos, mostrando una mayor concienciación y predisposición a las dietas saludables. 
El impacto de la publicidad en los hábitos alimenticios de los españoles: una cuestión de educación alimentaria

\section{REFERENCIAS}

Álvarez, I., Martínez, M. A., Sánchez-Tainta, A., Corella, D., Díaz, A., Fitó, M., Vioque, J., ... (2019). Dieta mediterránea hipocalórica y factores de riesgo cardiovascular: análisis transversal de PREDIMED-Plus. Revista española de cardiología, 72(11), 925-934. https://doi.org/10.1016/j.recesp.2018.08.007

Aranceta, J. et al. (2007). Prevention of overweight and obesity: a Spanish approach. Public Health Nutrition, 10(10A), 1187-1193. https://doi.org/10.1017/S1368980007000699

Ball, S. J. (2014). Globalización, mercantilización y privatización: tendencias internacionales en Educación y Política Educativa. Education Policy Analysis Archives/Archivos Analíticos de Políticas Educativas, 22, 1-13. http://dx.doi.org/10.14507/epaa.v22n41.2014

Boddewyn, J. J. (1988). Advertising self-regulation and outside participation: a multinational comparison. Quorum.

Baylis, J., Smith, P. y Owens, S. (2017). The Globalization of World Politics. An introduction to International Relations. Oxford University Press.

Cerri, Ch. (2010). La importancia de la metodología etnográfica para la investigación antropológica. El caso de las relaciones de valores en un espacio asociativo juvenil. Perifèria, 13, 1-32. https://doi.org/10.5565/rev/periferia.549

Chan, K., Prendergast, G., Grønhøj, A. y Bech-Larsenc, T. (2010). The role of socializing agents in communicating healthy eating to adolescents: A cross-cultural study. Journal of International Consumer Marketing, 23(1), 59-74. https://doi.org/10.1080/08961530.2011.524578

Comunidad de Madrid. (2017). Guía sobre el etiquetado nutricional de los alimentos. Madrid: Consejería de Sanidad de la Comunidad de Madrid.

Dani, C. (2019). Grape Juice and Soft Drinks: Take Care With the Sugar. EC Nutrition, 14(12), 1-6.

González, C., Meléndez, L. y Álvarez-Dardet, C. (2012). Alimentos como medicamentos: la delgada línea divisoria entre la industria farmacéutica y la industria alimentaria. Revista Española de Salud Pública, 86(4). http://scielo.isciii.es/scielo.php?script=sci arttext\&pid=S1135-57272012000400001

González, L. (coord.) (2015). Lecciones de derecho alimentario 2015-2016. Aranzadi.

Hansson SO. (2019). A Science-Informed Ethics for Agricultural Biotechnology. Crop Breed Genet Genom. https://doi.org/10.20900/cbgg20190006 
El impacto de la publicidad en los hábitos alimenticios de los españoles: una cuestión de educación alimentaria

Hayes, D. y Ross, C. E. (1989). Concern with Appearance, Health Beliefs, and Eating Habits. Journal of Health and Social Behavior, 28, 120-130. https://doi.org/10.2307/2137126

Hernández, A. (2013a). Progreso normativo en la orientación nutricional del consumidor: efectos sobre el etiquetado y la publicidad. 3C Empresa, 15, 43-60.

Hernández, A. (2013b). Los retos de la industria alimentaria ante la seguridad y los hábitos nutricionales saludables. 3C Empresa, 15, 6-21.

Higgins, Ch. (ed.) (2011). Identity Formation in Global Contexts. Language Learning in the New Millenium. Walter de Gruyter GmbH \& Co. KG.

Lobstain, T. y Davies, S. (2009). Defining and labelling 'healthy' and 'unhealthy' food. Public Health Nutrition, 12(3), 331-340. https://doi.org/10.1017/S1368980008002541

Marías, J. (1961). El método histórico de las generaciones. Revista de Occidente.

Menéndez, R. A. y Franco, F. J. (2009). Publicidad y alimentación: influencia de los anuncios gráficos en las pautas alimentarias de infancia y adolescencia. Nutrición Hospitalaria, 24(3), 318-325.

Mulders, M. D. (2019). To read or not to read: The influence of nutrition labels on the judgment and choice of food products [Tesis de doctorado no publicada]. Universidad Libre de Bruselas.

Newell, D. G. et al (2010). Food-borne diseases - The challenges of 20 years ago still persist while new ones continue to emerge. International Journal of Food Microbiology, 139, S3-S15.

Ortega y Gasset, J. (1947). Velázquez. Revista de Occidente.

Ortega y Gasset, J. (1952). Pasado y porvenir para el hombre actual. Obras Completas, T. 9. Revista de Occidente.

Ortega y Gasset, J. (1986). La rebelión de las masas (25를. ed.). Espasa Calpe (Colección Austral).

Pelletier, L. S. et al. (2004). Why do you regulate what you eat? Relationships between forms of regulation, eating behaviors, sustained dietary behavior change, and psychological adjustment. Motivation Emotion, 28, 245-77.

Pieterse, J. N. (2019). Globalization and Culture. Rowman \& Littlefield. 
El impacto de la publicidad en los hábitos alimenticios de los españoles: una cuestión de educación alimentaria

Pineda, M. (2002). Globalización, tecnologías de la información y diversidad cultural: homogeneización Vs diferencias. Revista Latina de Comunicación Social, 5(51). https://www.redalyc.org/pdf/819/81955105.pdf

Prado, C., Fernández del Olmo, R. y Anuncibay, J. (2007). Evaluación de la calidad de la dieta y su relación con el estatus nutricional en niños y adolescentes de 9 a 15 años de la ciudad de Madrid. Antropo, 14, 61-73.

Real Decreto (RD) 1334/1999, de 31 de julio, por el que se aprueba la norma general de etiquetado, presentación y publicidad de los productos alimenticios. 24 de agosto de 1999. https://www.boe.es/eli/es/rd/1999/07/31/1334

Reglamento (UE) 1169/2011 del Parlamento Europeo y del Consejo de 25 de octubre de 2011 sobre la información alimentaria facilitada al consumidor. DOUE L304 de 22 de noviembre de 2011. https://www.boe.es/doue/2011/304/L00018-00063.pdf

Rodrik, D. (2011). The Globalization Paradox: Democracy and the Future of the World Economy. WW Norton \& Company.

Robles, B. (2011). La entrevista en profundidad: una técnica útil dentro del campo antropofísico. Cuicuilco, 18(52), 39-49.

Samour, H. (2013). Globalización, cultura e identidad. ECA: Estudios centroamericanos. № 678-679, 475-489.

Sarkodie, N. A. y Boakye-Kessie, V. A. (2017). Assessing Consumer's Awareness of Food Labeling in Sunyani Municipality. ADRRI Journal of Agriculture and Food Sciences, $3(10,2), 1-10$.

Schoenebeck, S. Y. (2014). Developing healthy habits with social media: Theorizing the cycle of overuse and taking breaks. En: Proceedings of SIGCHI. https://yardi.people.si.umich.edu/pubs/Schoenebeck SocialMediaHabits14.pdf

Taylor, S. J. y Bodgan, R. (1984). Introduction to qualitative methods. Wiley.

Teixeira, P. J., Patrick H. y Mata, J. (2011). Why we eat what we eat: the role of autonomous motivation in eating behaviour regulation. British Nutrition Foundation Nutrition Bulletin, 36, 102-107.

Thaler, R. H. y Sunstein, C. R. (2009). Nudge: Improving Decisions About Health, Wealth and Happiness. Penguin.

Thorndike, A. N., Riis, J., Sonnenberg, L. M. y DSc, Levy, D. E. (2014). Traffic-Light Labels and Choice Architecture: Promoting Healthy Food Choices. American Journal of Preventive Medicine, 46(2), 143-149. https://www.sciencedirect.com/science/article/abs/pii/S0749379713005527 
El impacto de la publicidad en los hábitos alimenticios de los españoles: una cuestión de educación alimentaria

Wansink, B. (2006). Position of the American Dietetic Association: Food and Nutrition Misinformation. Journal of the American Dietetic Association, 106(4), 601-607. https://doi.org/10.1016/i.jada.2006.02.019

\section{AUTORES}

\section{Dr. Manuel Carmona Rodríguez}

Doctor en C.C. Comunicación por la U. de Sevilla. Profesor Asociado del Departamento de Comunicación y Sociología de la URJC. Imparte docencia de Principios de la Comunicación en español e inglés, de Fundamentos de la Comunicación y Estructura de los medios.

20 años de experiencia en publicaciones nacionales e internacionales. Escritor de novelas y ensayos: Autor de Love again (Total Recall Press, 2016) publicada en inglés y lanzada desde los Estados Unidos. Coautor del ensayo Acciones y Palabras (Planeta, 2013).

Periodista freelance para EL PAÍS y MAGISTERIO. Su blog periodístico Rick's Cafe fue reconocido como modelo de periodismo digital en la Tesis de Maestría de Silvana Belén Tecglia en la Universidad Interamericana de Buenos Aires.

ORCID: https://orcid.org/0000-0001-7724-2145] GOOGLE SCHOOLAR:

https://scholar.google.es/citations?user=vMOrbXIAAAAJ\&hl=es]

\section{Dra. Juana Ma Anguita Acero}

Doctora en Ciencias de la Educación por la U. Camilo José Cela. Licenciada en Traducción e Interpretación por la U. de Málaga. Licenciada en Filología Inglesa por la UNED. Máster en Educación Bilingüe por la Universidad Francisco de Vitoria.

Profesora Asociada del Departamento de Ciencias de la Educación, Lengua, Cultura, Artes, Ciencias Histórico-Jurídicas, Humanidades y Lenguas Modernas de la Facultad de Ciencias Jurídicas y Sociales de la Universidad Rey Juan Carlos.

Profesora colaboradora en el programa de estudios de la Licenciatura de Educación Infantil y Primaria de la Facultad de Ciencias Sociales de la Universidad Alfonso X El Sabio. Más de 10 años de experiencia como traductora especializada en localización de software y en educación internacional.

ORCID: orcid.org/0000-0002-8390-857X]

GOOGLE SCHOOLAR:

https://scholar.google.es/citations?user=QjGzop8AAAAJ\&hl=es] 